\title{
La mujer del emperador: Ana María Huarte de Iturbide. Un perfil biográfico (1786-1822)
}

The Emperor's Wife: A Biographic Profile of Ana María Huarte de Iturbide (1786-1822)

\section{José María Navarro Méndez}

Programa de Maestría en Historia

Universidad Autónoma de Sinaloa

josenavarro517@gmail.com

Recibido: 9 de febrero de 2018 - Aprobado: 5 de marzo de 2018

Cómo citar este artículo: José María Navarro Méndez, "La mujer del emperador: Ana María Huarte de Iturbide. Un perfil biográfico (1786-1822)", en Legajos. Boletín del Archivo General de la Nación, núm. 16 (mayo-agosto 2018), pp. 11 -34.

\section{Resumen}

El interés por la figura de Ana Huarte de lturbide radica en dos aspectos que queremos resaltar antes de exponer un perfil biográfico, el cual tiene la intención de centrarse en la nobleza del personaje, y su alza tras la culminación de la Independencia de México. La vida de una mujer "excepcional" representa un paradigma para la historia de la nación. Si bien Ana Huarte no ha tenido fuerte presencia en la historia patria, es ella la primera mujer destacable en el México Independiente. Por último, salvarla de la invisibilidad histórica es un proyecto que parte de la historia del género que busca introducir a la mujer en el relato universal del hombre y mostrar que la misma Ana Huarte no es solo un personaje anecdótico o decorativo del mismo lturbide como la historiografía mexicana la ha mostrado.

\section{Palabras clave: Ana María} Huarte, Agustín de lturbide, mujer excepcional, emperatriz, Independencia

\section{Abstract}

This biographical profile focuses on the nobility of Ana Huarte de Iturbide and her rise after the culmination of Mexico's Independence. The life of an "exceptional" woman represents a paradigm for the history of the nation. Although Ana Huarte has not had a strong presence in Mexican history, she is the first remarkable woman in the early independence era. Rescuing her from historical invisibility by showing that Ana Huarte was more than an anecdotal or decorative figure for Iturbide, as Mexican historiography has portrayed her, responds to efforts in gender history to insert women into the universal history of man.

Keywords: Ana María Huarte, Agustín de lturbide, exceptional woman, empress, Independence 


\section{Introducción}

Ana María Huarte "la primera mexicana", 1 es la mujer que por excelencia ha sido borrada de la historia nacional, una mujer excepcional que ha sido olvidada por los hechos que directa o indirectamente la vinculan con Agustín de Iturbide. Con este perfil pretendemos abordar el entender de una mujer noble, que fue partícipe de la transición de lo novohispano a lo mexicano, bajo el ala del primer gobierno independiente de México.

El papel histórico de Ana Huarte ha sido pasado de largo. Se le ha visto como un personaje de adorno, anecdótico y subordinado a la figura de Iturbide. Tanto la historiografía de bronce como las contribuciones más contemporáneas la han sujetado a su esposo. Los aportes de Carlos María de Bustamante, las observaciones de Lucas Alamán, las críticas de Vicente Rocafuerte e incluso José Malo -que siendo pariente político de ella-, describieron de manera anecdótica y decorativa su destino tras la muerte de Iturbide. ${ }^{2}$ Por su lado, los historiadores contemporáneos tampoco han realizado un atinado balance del personaje, así ha ocurrido con William Spence Robertson, Josefa Vega Juanino, Timothy Anna; ${ }^{3}$ siendo la excepción Moisés Guzmán Pérez, quien en los últimos años se ha dedicado a estudiar las figuras de las mujeres insurgentes, y ha realizado un corto perfil biográfico de Ana María Huarte en revistas de difusión cultural. ${ }^{4}$

${ }^{1}$ El término lo utilizamos con la intención de establecer un punto y aparte en relación con la historia de bronce. Proponiendo que Ana Huarte de Iturbide, al ser la compañera de vida del líder que culmino la Independencia de la Nueva España, se presenta como la mujer de mayor peso político y social, con respecto al resto de sus coetáneas, lo cual se manifestó durante su entrada pública a la ciudad de Valladolid de Michoacán, en agosto de 1821.

${ }^{2}$ Alamán, Disertaciones sobre la historia de Méjico; Bustamante de, Cuadro histórico; Rocafuerte, Bosquejo ligerísimo; Malo, Apuntes sobre el destierro.

${ }^{3}$ Spence Robertson, Iturbide de México; E. Anna Timothy, El Imperio de Iturbide; Vega Juanino, Agustín de Iturbide.

${ }^{4}$ Guzmán Pérez, "Las mujeres michoacanas en la Independencia”, pp. 3-24. 
El marcado romanticismo que se le ha impreso a Ana Huarte, le ha valido la elaboración de novelas históricas, las cuales brindan una somera impresión del personaje que se iluminó fugazmente tras la arenga pública que llamó a Agustín de Iturbide a tomar el trono de México. Rosa Beltrán ha elaborado complejas interpretaciones teñidas de rosa de aquel contexto. ${ }^{5}$ Por nuestra parte, hemos realizado un trabajo biográfico el cual ha intentado abarcar tanto los aspectos personales de Ana Huarte, como las complejas relaciones que vivió en tiempos de guerra, y hemos intentado establecer una interpretación sobre el tipo de relación que mantuvo con la alta sociedad cortesana ya fuera en tiempos del Imperio o en la Corte española. ${ }^{6}$

Con la intención de precisar el uso de las fuentes de las que nos hemos valido, dirigimos una pequeña crítica, pues dentro de las dificultades para su interpretación está la que emana de la particularidad de su uso. Debemos recordar a nuestro lector que se trata de la historia de una mujer y no es que por ello se haya tratado de demeritar su vida, sino que el uso de los acervos muchas veces es dirigido por hombres, de allí la necesidad de escarbar, rastreando incluso los pequeños indicios. A través de los archivos locales de la Ciudad de México, Morelia y de Querétaro, nos adentramos en la vida particular de Ana Huarte. Las fes de bautizo forman un gran material de interpretación histórica sobre todo en la construcción de las relaciones sociales, los libros de matrimonio de igual manera atienden dichas necesidades, así también las sesiones de los cabildos civil y eclesiástico, nos permiten, no sin dificultades, encontrar los hilos conductores de una historia tan particular.

\section{La juventud de Ana Huarte}

Ana María Josefa Ramona Juana Nepomucena Marcelina Huarte y Muñiz nació en la ciudad de Valladolid de Michoacán, capital de la

\footnotetext{
${ }^{5}$ Beltrán, La corte de los ilusos.

${ }^{6}$ Navarro Méndez, La mujer del emperador.
} 
Intendencia de Michoacán, el 18 enero de 1786 en casa paterna. La pequeña infanta, fue la sexta hija legítima del alcalde provincial Isidro Huarte y Arrivillaga y de la noble criolla Ana Manuela Sánchez de Tagle. ${ }^{7}$ Prominente familia de la intendencia cuyo poder no solo fue económico, sino que se extendía sobre lo social, lo político e incluso cubría al clero de todo Michoacán. Por el lado de su madre fue sobrina - casi hija- de Pedro Anselmo Sánchez de Tagle. Su padre forjó una enorme fortuna tras haber llegado a la Nueva España. La joven vallisoletana fue bautizada por el canónigo de la catedral Blas Echeandia, seguramente la celebración por el feliz acontecimiento acarreó tanto a amigos como a conocidos. Los padrinos de la pequeña fueron José Plata, regidor de la ciudad, y su esposa Ana Bustamante, a quienes en la ocasión amonestaron para cumplir sus obligaciones cristianas. ${ }^{8}$

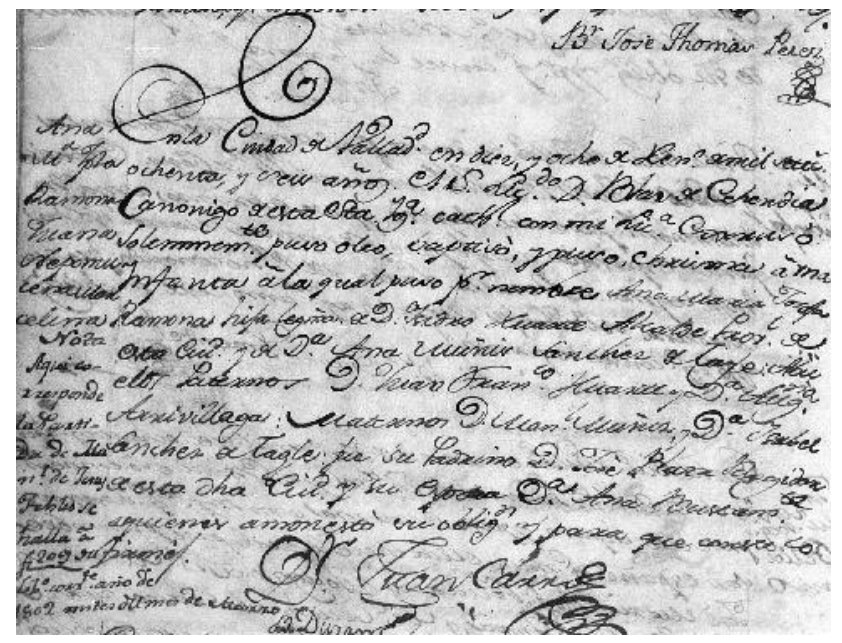

Fuente: Sobre la fe de bautismo de Ana María Huarte.

Extraído del libro de bautizos de españoles.

7 Guzmán Pérez y Barbosa Malagón, "Lecturas femeninas en Valladolid de Michoacán", pp. 15-70.

8 "Fe de bautismo de Ana Huarte", 18 enero de 1786, Archivo de la Notaria Parroquial del Sagrario de Morelia (en adelante APSM), Bautismos de españoles, libro 32, años 1780-1786, f. 162v. 
Pocos datos tenemos de la cómoda vida que debió tener Ana Huarte; con la intención de no especular y evitar caer en algún anacronismo, preferimos limitarnos a marcar la idea de que su vida fue opulenta; de pequeña debió pasar innumerable cantidad de horas jugando por los pasillos de la enorme mansión de los Huarte y Muñiz, y de vez en vez en las haciendas y ranchos de su padre, junto a las niñas de su clase y edad, antes de ingresar al Colegio de Santa Rosa de Valladolid.

Seguramente, Ana, al igual que sus hermanas, desde corta edad comenzó a interesarse por la lectura, dado que su madre fue una ávida lectora, y como han mostrado Moisés Guzmán y Patricia Barbosa, la librería de la señora Manuela Sánchez de Tagle contaba con un abundante número de libros dedicados al catecismo, a la historia vasca, a la educación, a la aritmética y a la inculcación de los valores morales hispanos. ${ }^{9}$ Las tertulias formaron parte continua de sus actividades semanales, quizás con círculos de lectura cristiana, relacionándose en ellos con las demás damas de abolengo de la ciudad. También cabe que dentro de la casa de los Huarte se llevaran a cabo algunas reuniones de la Sociedad Vascongada de Amigos del País, entre cuyos miembros afiliados estuvieron los Huarte, los García Obeso, los Iturbide, entre otros; no dudamos que la curiosidad infantil llevara a Ana María a fisgonear las discusiones de aquellos clérigos, comerciantes y militares, los cuales eran acompañados por sus esposas que, apostadas en otro espacio, debieron platicar sobre las modas y las agitaciones que se suscitaban en el reino. Y claro, todo siempre acompañado por una taza de champurrado o de chocolate. ${ }^{10}$

Con el correr de los días Ana María entró al Colegio de Santa Rosa de Valladolid, cuyo principio era proteger a las "... Rosas de Castilla, sin mezcla de otras flores, todas españolas..."; ahí su vida comenzó a cambiar de manera paulatina. ${ }^{11}$ Es posible que fuera

9 Guzmán Pérez y Barbosa Malagón, "Lecturas femeninas en Valladolid de Michoacán", pp. 61-62.

${ }^{10}$ Juárez Nieto, La oligarquía y el poder político, p. 157.

${ }^{11}$ Carreño Alvarado, El Colegio de Santa Rosa de Valladolid, p. 35. 
inscrita en el colegio entre 1796-1798, cuando apenas tenía entre 10 y 12 años de edad, aunque Gloria Carreño nos dice en su obra que la media de ingreso entre las alumnas oscilaba entre los 15 y 25 años. ${ }^{12}$ De cualquier manera, entre 1795 a 1797, cuando Ana María entró a Santa Rosa, la administración del colegio estaba en manos de Gabriel García Obeso, siendo la rectora del establecimiento, doña Gertrudis López y su vicerrectora doña Guadalupe Castro. ${ }^{13}$

Pese a ser hija de uno de los patrocinadores de la institución, ${ }^{14}$ Ana María seguramente ingresó bajo los mismos términos que las demás educandas. Los requisitos eran estrictos, los cuales incluían el ser español; lo cual era comprobado mediante la fe de bautismo y un documento llamado Información de Pureza de Sangre que consistía en cuatro o cinco testimonios jurados, hechos por vecinos de muy buena reputación. ${ }^{15}$ Para los Huarte y Muñiz ese trámite no debía presentar ningún problema, aunque debemos tener en consideración que la exhibición de la pureza sanguínea era un acto que podía ser visto como deshonroso, cuyo significado menguaba el honor familiar. La idea y el hecho de ingresar al colegio a estudiar, forma parte de la tradición familiar de los Huarte y Muñiz. Ana, al igual que su madre ${ }^{16}$ y sus hermanas María del Carmen y María Teresa, fueron alumnas hasta antes de que contrajesen matrimonio. ${ }^{17}$

${ }^{12}$ Carreño Alvarado, El Colegio de Santa Rosa de Valladolid, p. 131.

13 "Organización interna del Colegio de Santa Rosa de Valladolid", año de 1796, Archivo Histórico Casa de Morelos (en adelante Aнсмо), Colegios, Santa Rosa, S. XvIII, C. 21, Exp. 290, 2 expedientes, f. 20. En el primer expediente se encuentra referido el cambio de administración interna, la nueva rectora da aviso al obispo Fray Antonio de San Miguel del hecho, así da la lista con todas las encargadas que llevan a cuestas el colegio a partir de 1797, fechada el 6 de diciembre de 1796. En el segundo expediente refiere una demanda que por falta de pago el administrador Gabriel García Obeso, así mismo existe otro documento con fecha de 6 diciembre de 1803 en la cual se ratifica el rectorado de las mismas personas.

${ }^{14}$ Carreño Alvarado, El Colegio de Santa Rosa de Valladolid, p. 130.

${ }^{15}$ Carreño Alvarado, El Colegio de Santa Rosa de Valladolid, p. 127.

${ }^{16}$ Guzmán Pérez y Barbosa Malagón, "Lecturas femeninas en Valladolid de Michoacán", p. 27.

${ }^{17}$ Navarro Méndez, La mujer del emperador, p. 35. 
Si recordamos los escritos de Silvia Arrom, entenderemos que la educación de Ana Huarte forma parte de las ideas ascendentes de la nobleza, así como de la burguesía novohispana, pues los noblesburgueses ven la posibilidad de que la mujer fuera sujeto del entendimiento, ya que se buscaba que ellas alcanzaran un conocimiento por lo menos mínimo, ${ }^{18}$ sosteniendo siempre que el indicativo según la preferencia social era que la mujer llevase una vida familiar o una vida espiritual. ${ }^{19}$ De igual manera, Gonzalbo Aizpuru ha expresado que el entendimiento de las mujeres, vislumbrado elegantemente y con alegre cortesía, que a juzgar por la firmeza y el conocimiento de muchas de ellas - después de la segunda mitad del siglo XvIII- éstas estaban bien educadas, al menos tanto como los varones. ${ }^{20}$

La estancia de Ana María en el Colegio de Santa Rosa de Valladolid, seguramente fue parecida al de las demás estudiantes, centrando su vida estudiantil en las tareas de las virtudes; la compostura, la modestia, el habla, la buena conducta y el conducirse con moral; también se les indujo a la música. Las clases de estas materias eran obligatorias, las cuales tenían la finalidad de hacer que las niñas se acercaran a una vida santa. ${ }^{21}$ Casi es seguro que, entre las tantas obligaciones de las señoritas, se les inculcara de igual forma la escritura y las matemáticas elementales a través de las "amigas". 22

\footnotetext{
${ }^{18}$ Arrom Silvia, Las mujeres de la Ciudad de México, p. 216.

19 Guzmán Pérez y Barbosa Malagón, "Lecturas femeninas en Valladolid de Michoacán", p. 12.

${ }^{20}$ Gonzalbo Aizpuru, "Orden, educación y mala vida", p. 24.

${ }^{21}$ Perrot, Michelle, Mi historia de las mujeres, p. 129.

22 "Las Amigas", 1796, Aнсmo, Colegios, Santa Rosa, S. XVIII, caja 21, exp. 290, 2 expedientes, f. 20. El archivo indica a las mujeres que ejercían ese papel. La función de este grupo de mujeres era que se encargaban de impartir las nociones más elementales de aritmética, lectura y escritura. No les estaba permitido tener grupos mixtos. Dichas mujeres, generalmente ancianas o solteras no estaban muy preparadas [cabe destacar]. En los expedientes se indica que entre las maestras "amigas" o maestras de "afuera" destacan los nombres de Manuela de Olmos, Margarita Tamayo y Josefa Ariz; Carreño Alvarado, El Colegio de Santa Rosa de Valladolid, p. 26; Fernández de Lizardi, La quïotita, pp. 59-60.
} 
Como estudiante permanente del colegio, Ana Huarte estuvo aferrada a la vida cuidadosamente condicionada y planeada; pero en los recesos, las señoritas se acercaban de manera un tanto curiosa al mirador del colegio, con la intención de lucirse ante los que en las calles caminaban. Ha sido muy divulgado que de esta manera Ana María conoció al entonces teniente de segundo grado del Regimiento de Infantería de Valladolid, ${ }^{23}$ al criollo Agustín Cosme Damián de Iturbide y Aramburu. Seguramente Iturbide pasaba las tardes pavoneándose frente al Colegio de Santa Rosa, intentando llamar la atención de las señoritas.

Atrayendo la atención de Ana María, la fortuna tocaría el dintel de Agustín. Si bien, el himeneo de los jóvenes vallisoletanos, fue consensado y se dio bajo la bandera del amor, ${ }^{24}$ hay que tener en cuenta la solvencia económica y el prestigio social de los Huarte, que superaban a los de los Iturbide. Bajo dicha circunstancia, resultó favorecido Agustín de Iturbide al matrimoniarse con la noble criolla.

El 27 de febrero de 1805, contrajeron matrimonio Ana Huarte y Agustín de Iturbide, sin la oposición de las familias, en presencia del provisor general capitular del obispado, el doctor Juan Antonio de Tapia. Ella, con 19 años de edad y él con 21 años; se presentaron como padrinos de la pareja Isidro Huarte, por parte de la novia, y por parte del novio Domingo Malo, quien era cuñado de José de Iturbide. La misa nupcial se celebró al día siguiente en el oratorio de la casa de los recién casados en lo que hoy conocemos como portal Galeana número 117. ${ }^{25}$ Aquí, el hermano de Ana, Isidro, y Nicolasa, hermana de Agustín, junto con el intendente de Valladolid Felipe Díaz de Ortega, firmaron la certificación. ${ }^{26}$ Es casi seguro que la feliz pareja recibiese la dote por parte de la novia, ya que esta rica heredera tuvo la fortuna

${ }^{23}$ Spence Robertson, Iturbide de México, p. 46.

${ }^{24}$ Spence Robertson, Iturbide de México, p. 46.

${ }_{25}$ Spence Robertson, Iturbide de México, p. 47. Hoy en día, en lo que fue la casa particular de Agustín de Iturbide se encuentra un hotel-bar.

26 "Certificación de matrimonio de Agustín de Iturbide y Ana Huarte", 27 de febrero de 1805, APSM, Matrimonios de españoles, libo 15, años 1789- 1806, f. 174 v. 
de haber recibido de su padre, hasta antes de 1821, poco más de treinta mil pesos.

Llegado a este punto, la vida de Ana María cambió drásticamente en su día a día. Aquí se puede sacar a colación que la situación de Ana María, por lo menos antes de febrero de 1805, era particularmente de esplendor, es decir, el lujo y la opulencia la acompañaban. Si bien no se puede tener información precisa de su infancia, debido a la falta de atención que se tenía de la memoria femenina, sí observamos que Ana María fue una mujer letrada y de principios, valores que su madre le inculcó. Cabe resaltar, también, que nuestro personaje se desarrolló con los sectores más importantes de Valladolid, definiendo su modo de proceder, como el de una española americana de prestigiosa posición.

La vida de madre no fue sencilla, más aún si las circunstancias políticas y sociales se suman a la fórmula. Para el año de 1806, la vida de Ana María había cambiado de manera paulatina, la comodidad económica y el desasosiego que se podía tener fue progresivamente sustituido por la angustia. ${ }^{27}$ En ese mismo año nació el primogénito de los Iturbide Huarte, y sería exactamente ese mismo año cuando Agustín de Iturbide fue enviado al acantonamiento en Xalapa, según se registra en las órdenes del virrey Iturrigaray. ${ }^{28}$ Los días venían y las noches corrían, y las epístolas entre Ana María y Agustín de Iturbide circulaban. Las que iban, llevaban noticias, cuando menos chismosas, y lo cierto es que las que leía Ana eran parecidas. La alegría llegaría cuando en una de las cartas que envió Iturbide, ${ }^{29}$ anunciaba que había sido ascendido y se le había concedido una dispensa debido a lo insano del clima. ${ }^{30}$

Los levantamientos políticos suscitados en 1808, 1809 y 1810, trasforman por completo la realidad de los novohispanos, enfrentando y dividiendo familias enteras. En la intendencia de Valladolid, tras los

\footnotetext{
${ }^{27}$ Navarro Méndez, La mujer del emperador, p. 48.

${ }^{28}$ Vega Juanino, Agustín de Iturbide, p. 25.

${ }^{29}$ Navarro Méndez, La mujer del emperador, p. 49.

${ }^{30}$ Gutiérrez Casillas, Papeles de don Agustín de Iturbide, pp. 31-37.
} 
acontecimientos que dieron pie a la guerra civil, Iturbide y su familia salieron de la capital michoacana con rumbo a México; los miedos que infundió la insurgencia que encabezada por Hidalgo golpearon de lleno. ${ }^{31}$ Las referencias documentales nos han indicado que Iturbide, junto con su familia, su esposa y algunos criados pasaron a la hacienda de Apeo donde, tras una corta estancia, marcharon rumbo a la Ciudad de México. ${ }^{32}$ Debemos tener en cuenta que entre los criados de la familia la presencia de una nodriza debió ser segura, pues "la buena o la mala constitución de los niños [era encomienda] de una nodriza robusta y cuidadosa de sus obligaciones", ${ }^{33}$ siendo pues, ella, una segunda madre para los infantes. La presencia de la nana no es descabellada pues las prácticas de crianza cotidiana de la época así lo marcaban.

Para estos años, el segundo embarazo de Ana María se estaba gestando, ${ }^{34}$ mientras Iturbide combatía a los insurgentes en Maravatío, Ana enfrentaba las molestias que son propias del embarazo. Si bien, habremos de referir, las mujeres novohispanas tenían una serie de prácticas comunes, por ejemplo, algunas de las cuales Martha Eugenia Rodríguez ha señalado: “...sin temor ni vergüenza ellas, las embarazadas, no debían restringirse de pedir lo que se les antojará, pues de no cumplirse dicho antojo la criatura corría peligro..." ${ }^{35} \mathrm{Y}$ con la finalidad de evitar los sustos, que ya para esos años eran muy difíciles de evitar, las parturientas seguramente se encomendaban a san Ramón Nonato, siempre ayudando con la ingesta de un antiepiléptico compuesto de láudano, vino blanco, azafrán, y otras substancias como canela y jarabe de rosas. ${ }^{36}$ A lo largo de su matrimonio Ana María, daría a luz a

${ }^{31}$ Guzmán Pérez, Miguel Hidalgo y el gobierno, p. 189.

${ }^{32}$ Spence Robertson, Iturbide de México, p. 55.

${ }^{33}$ Fernández de Lizardi, La quijotita, p. 27.

34 "Fe de bautismo de Sabina de Iturbide", 01 de enero de 1811, Archivo Parroquial de San Miguel de Arcángel México (en adelante APSMAM), Bautismo de españoles, libro 23, años 1808-1816, f. 178v. La pequeña infanta nació tan solo dos meses después de la batalla del Monte de las Cruces, su bautizo se realizó en la Ciudad de México.

${ }^{35}$ Rodríguez, "Costumbres y tradiciones en torno al embarazo", pp. 503-504.

${ }^{36}$ Rodríguez, "Costumbres y tradiciones en torno al embarazo", p. 504. 
diez hijos, de los cuales solo María de los Dolores, fenecería en 1819 a meses de haber nacido; a diferencia de esta última, los retoños de Agustín y Ana tendrían vidas largas y relativamente bien acomodadas. ${ }^{37}$

El hecho de pasar a México, marcó un cambio de ritmo en el día a día de Ana Huarte. No existe punto de comparación entre Valladolid y la capital del reino; la dimensión poblacional, la extensión de las calles y el gran ajetreo que irradiaba la ciudad debieron sobrecoger a Ana Huarte. Hasta donde las fuentes nos han llevado, la familia se estableció en la calle Tiburcio número siete (hoy calle de República de Uruguay), según lo indican los registros parroquiales. ${ }^{38}$

Es interesante resaltar que, en aquellos años de guerra, la mayoría de los militares llevaban consigo a sus compañeras de vida a las campañas; se ha señalado que la Generala María Francisca de la Gándara de Calleja acompañó en todo momento al general Félix María Calleja; y estuvo presente en el sitio de la villa de Zitácuaro. ${ }^{39}$ En efecto, en enero de 1812, Iturbide destacó en su diario de guerra que cuando acampó cerca de Maravatío, ${ }^{40}$ Calleja estuvo en el mencionado pueblo haciendo los preparativos necesarios para emprender el asedio a la villa de Zitácuaro. Agustín escribió en su diario de guerra que “... en esta jornada nos acompañaba la señora Generala, Madame amabilísima y llena de mérito"; ${ }^{41}$ luego puntualizando que "...pasé a Pateo, con idea de saludar a algunos amigos y compañeros de armas, y de conocer al hombre grande, al señor Calleja; lo logré en efecto, y tuve la

${ }^{37}$ Navarro Méndez, La mujer del emperador, pp. 69-152.

38 "Acta de entierro de Dolores Iturbide hija de Ana Huarte y Agustín de Iturbide", mes de junio de 1818, Archivo de la Parroquia del Sagrario Metropolitano de México (en adelante APSMM), Entierro de españoles, caja 226, libro 2, años 1818-1820.

${ }^{39}$ Núñez y Domínguez, La virreina mexicana, pp. 174-175.

${ }^{40}$ Iturbide, "Diario Militar Particular de D. Agustín de Iturbide y Aramburu, el que lleva en sus expediciones..., Año de 1812 enero", 20 de enero de 1812, en Archivo General de la Nación, Documentos para la historia de la guerra de Independencia, 1810-1821. Correspondencia y diario militar de Iturbide, 1810-1813, t. I, México, Imprenta Manuel León Sánchez, 1923, p. 97.

${ }^{41}$ Iturbide, "Diario Militar Particular de D. Agustín...", 20 de enero de 1812, p. 97. 
satisfacción de verle abrazar a su amable Madame; al señor Rendón; a su apreciable Margarita, hermana, y preciosas chiquitas..." ${ }^{42} \mathrm{Y}$ es que, al contrario de lo mencionado, Ana María Huarte permaneció siempre bajo el resguardo de la ciudad ya fuera en México, León o Querétaro. ${ }^{43}$

De lo anterior destacamos las prácticas de sociabilidad que tenían, tanto Agustín de Iturbide, como Ana María; pues en la medida de lo posible, Ana se mantuvo fuera de la escena política, ${ }^{44}$ por lo menos de la opinión pública. La vida familiar nunca ha sido fácil, especialmente cuando le agregamos los embates de la guerra. Las acusaciones que Iturbide sufrió en 1815 y 1816, cuando estaban a su mando las tropas de los Ejércitos del Norte, golpearon la honorabilidad de su familia, marcando el devenir social de Ana Huarte. Fue en el Bajío donde las increpaciones del doctor Antonio de Labarrieta, ${ }^{45}$ hicieron abrir un caso judicial en contra de Iturbide por malversación durante su posición. La fama de inhumano y la crueldad que había caracterizado a Iturbide seguramente llegaron a oídos de Ana María, llevando a la familia a una crisis moral y espiritual.

Las acusaciones fueron tan graves que el virrey Calleja pidió a Agustín trasladarse a la capital de inmediato, la vergüenza manchó el honor de Ana María, pues el 10 de abril de 1816, ${ }^{46}$ Iturbide estaba enfrentando las acusaciones imputadas por los guanajuatenses. Ana María acompañó a su esposo en todo momento, y por un lapso de varios meses él defendió su posición ante las acusaciones de malversación de fondos, diciendo que no podría tener mayor gloria que la de derramar su sangre en defensa de su santa religión, de un rey justo y de una patria amada. ${ }^{47}$

${ }^{42}$ Iturbide, "Diario Militar Particular de D. Agustín...", 22 de enero de 1812, p. 98

${ }^{43}$ Navarro Méndez, La mujer del emperador, p. 59.

${ }^{44}$ Navarro Méndez, La mujer del emperador, p. 65.

${ }^{45}$ Spence Robertson, Iturbide de México, p. 82.

${ }^{46}$ Calleja a Iturbide, 4 de abril de 1816, en Archivo General de la Nación, Documentos para la historia de la Guerra de Independencia, 1810-1821. Correspondencia y diario militar de Iturbide, t. III, México, Archivo General de la Nación, 1926, p. 338.

${ }^{47}$ Cuevas, El libertador: Documentos selectos, pp. 124-167. 
Es, a partir de este punto histórico, donde las exageraciones y las increpaciones de los enemigos políticos y militares de Iturbide ridiculizan la existencia de Ana y su familia. La acusación más notable es la que ha dejado Vicente Rocafuerte, pues en sus extensas reflexiones afirma que es durante este inter ${ }^{48}$ que Agustín conoció a la güera Rodríguez, siendo peculiares las afirmaciones que hace Rocafuerte. Éste describe los hechos de manera poco fiable diciendo que:

...contrajo trato ilícito con una señora principal de México, cuya reputación de preciosa rubia, seductora hermosura, llena de gracia, de hechizo y talento [...] llegó a tomar [con] tal violencia al corazón de Iturbide, que lo cegó al punto de cometer la mayor bajeza que puede cometer un marido; con el objeto de divorciarse de su esposa... ${ }^{49}$

Sinceramente este capítulo de la vida de Ana María y Agustín es exagerado, no por el hecho del adulterio, sino por la supuesta petición de divorcio; se deben considerar diversos factores ante las determinaciones descritas. Iturbide debía afrontar el forzoso retiro del real servicio de armas, mientras se realizaba la investigación en su contra. En agosto, Labarrieta se quejaba de Iturbide por haberse enriquecido de manera ilícita; y es que la familia Iturbide Huarte tenía enormes deudas que no pudo cubrir sino hasta septiembre de 1816 con la llegada del virrey Apodaca; fue entonces que las acusaciones en contra de Agustín de Iturbide quedaron en letra muerta, y un mes después Ana dio a luz a un hijo en Querétaro. ${ }^{50}$

${ }^{48}$ Refiere al tiempo que transcurre de 1815 a 1820, en el cual la vida de Agustín de Iturbide se ve bifurcada entre las acusaciones en su contra y los preparativos de los planes políticos. Véase Spence Robertson, Iturbide de México, pp. 77-97.

${ }^{49}$ Rocafuerte, Bosquejo ligerísimo, 1822, p. 21.

50 "Fe de bautizo de Ángel de Iturbide", 07 de octubre de 1816, Archivo de la Notaria Parroquial de la Iglesia de Santa Ana de la ciudad de Santiago Querétaro (APSAQ), Bautismo de Españoles, Años 1809-1824, f. 137. 
Durante estos años la vida económica de los Iturbide Huarte, fue muy precaria, teniendo que recurrir a Isidro Huarte en más de una ocasión para solventar los gastos familiares. Existe poca documentación personal sobre lo mencionado, pero en abril de 1817 Iturbide escribió a su

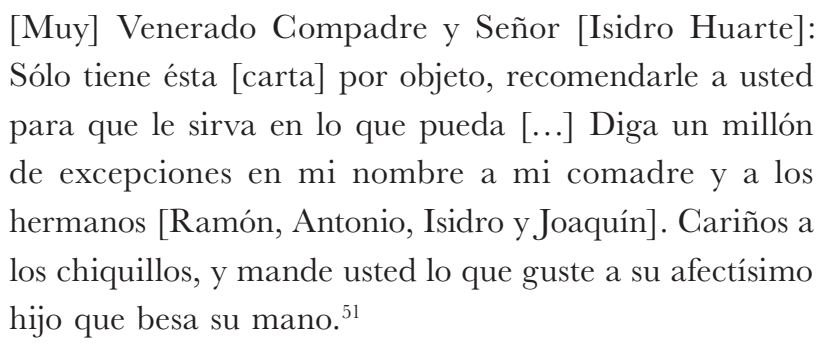

El desarrollo de la vida de la familia Iturbide y Huarte en este periodo, es postrado ante las marejadas de sus enemigos, que años después escribirían los actos que de la memoria colectiva no se han olvidado. Sin duda, ante las acusaciones, la falta de solvencia económica y el desatino social que se les marcó en las esferas grandilocuentes de la capital del virreinato, Ana debió pasar a segundo o incluso a tercer término en su estatus en cuanto a la convivencia social y la percepción que se tenía de ella. El rescate financiero que el padre dio a Ana fue el impulso para sustentar los planes de cambios que Iturbide comenzaba a lucubrar. ${ }^{52}$

\section{Lo político de Ana Huarte: su entrada pública a Valladolid}

Para los años de 1820-1821, la revolución de los militares, encabezada por Agustín de Iturbide, comenzó a movilizar las ideas de la sociedad, así como a los militares y políticos. El Plan de Iguala y sus ratificaciones bajo el nombre de los Tratados de Córdoba, afirmaron

${ }^{51}$ Gutiérrez Casillas, Papeles de Don Agustín de Iturbide, pp. 9-10.

${ }^{52}$ Navarro Méndez, La mujer del emperador, pp. 68-69. 
en la Nueva España que el rompimiento con la monarquía hispana era necesario según la realidad histórica, proponiendo de esa manera la idea de instalar un gobierno independiente y soberano que se denominaría Imperio Mexicano. ${ }^{53}$

Ante el escenario imperante que controlaba el Ejército de las Tres Garantías, para julio de 1821, ${ }^{54}$ Agustín de Iturbide, con el propósito de mantener el enclave de su ciudad natal, ideó el mandar a su esposa a Valladolid, con la finalidad de generar presión política y concretar el apoyo total de la urbe. Si bien, como afirmamos arriba, Iturbide intentó no involucrar a su familia en las vicisitudes de la guerra y la política, la partida de Ana Huarte a su hogar natal responde a la búsqueda de la representatividad trigarante; además, ella debió informar de la situación que prevalecía en la capital novohispana. De ese modo, Ana, junto con sus hijos, se trasladaron desde México en un viaje que fue, cuanto menos largo y cansado. ${ }^{55}$

Iturbide y las autoridades civiles de Valladolid de Michoacán, ya tenían, desde principios de marzo, anunciada la presencia de Ana Huarte en la ciudad, y comenzaron a preparar la entrada de la esposa del jefe trigarante, así lo denota el acta que levantó el cabildo del ayuntamiento, el 24 de marzo de $1821,{ }^{56}$ la cual indicaba que el cabildo con alcalde constitucional de primera instancia del Ayuntamiento de Valladolid de Michoacán, ${ }^{57}$ conocía "la intención de la entrada de doña Ana Huarte de Iturbide”. El oficio indica que se prepararía una misa en la catedral para dar gracias al todo Poderoso por la llegada de la señora de Iturbide.

\footnotetext{
${ }^{53}$ Arenal Fenochio, Un modo de ser libres; Ávila Alfredo, En nombre de la Nación.

${ }^{54}$ Guzmán Pérez, "El movimiento Trigarante", p. 149.

${ }_{55}$ Navarro Méndez, La mujer del emperador, p. 79.

56 "Cesión de Cabildo de mayo", mayo de 1821, Archivo Histórico Municipal de Morelia (en adelante AHMM), Libros de Actas de Cabildo, 1816-1821, libro 120, ff. 162 v.-163 v. Nota: El acta del cabildo la menciona como la esposa del jefe de las Tres Garantías o jefe Trigarante.

${ }^{57}$ Hacemos una precisión aquí, ya que el alcalde constitucional, era Ramón Huarte, hermano de Ana Huarte.
} 
Los acuerdos se firmaron y dieron fe de lo señalado haciendo ver que el Ayuntamiento de Valladolid, era una de las ciudades más comprometidas con el proyecto Imperial, pues desde antes de la capitulación de la Ciudad de México, la capital michoacana proyectó una imagen de compromiso. La fiesta que se comenzaba a planear y los gastos que se vislumbraban responden a una serie de emociones encendidas, pues el proyecto político de Agustín de Iturbide tenía la suficiente fuerza y aceptación generalizada en la sociedad. Por lo menos eso muestra la parte oficial, pues si bien Ramón Huarte es familiar tanto de Ana como de Iturbide, la ciudad manifiesta una actitud deseosa de la independencia; recordemos que para esas fechas era bien sabido el estado del proyecto iturbidista, el cual se encontraba próximo a la capitulación de la Ciudad de México.

Así pues, entre los días del 13 y 14 de agosto de 1821, Ana y sus hijos se pondrían en marcha rumbo a Valladolid de Michoacán, junto con una pequeña escuadra de dragones, quienes tuvieron la tarea de protegerlos. ${ }^{58}$ La familia Iturbide Huarte se puso en marcha con la bendición de Agustín y la de su fiel confidente el obispo Antonio Joaquín Pérez. ${ }^{59}$

Debido al mal estado de los caminos, el viaje fue cansado. Pese a los atrasos que se pudieran haber dado, Ana María llegó a su destino en tiempo (normalmente, las diligencias que salían de México con rumbo a Valladolid tardaban entre 8 y 10 días en llegar); las fuentes nos refieren que el 21 de agosto $^{60}$ estaba entrando a la ciudad $-\mathrm{y}$ vaya entrada que tuvo- pues las autoridades gubernativas y eclesiásticas ya los esperaban. ${ }^{61}$

Fue deleite de propios y extraños la llegada de Ana Huarte. Si bien Iturbide celebró su entrada a la Imperial Ciudad de México

\footnotetext{
${ }^{58}$ Navarro Méndez, La mujer del emperador, p. 79.

${ }^{59}$ Navarro Méndez, José María, “Ana María Huarte de Iturbide”, pp. 35-36.

60 "Misa a Ana Huarte", 21 de agosto de 1821, Archivo Capitular de la Catedral de Morelia (en adelante ACCM), Actas de Cabildo, libro 47, año 1819-1821, ff. 168 v-175 v. ${ }^{61}$ Navarro Méndez, “Ana María Huarte de Iturbide”, p. 37.
} 
como César Augusto a Roma, para Ana María fue como si la zarina Catalina la Grande arribara a San Petersburgo. Varios relatan el gran suceso; por ejemplo, Joaquín Fernández de Córdoba, recuperó folletería del periodo la cual asegura que:

...las patrióticas e ilustres opiniones de los vallisoletanos, [por] el recibimiento que se le hizo ha sido uno de los espectáculos más lúcidos y pomposos que se haya visto jamás en [...] la ciudad de Valladolid [que en] todas [sus] calles estaban sembradas de flores y desde lo alto de los edificios doncellas graciosamente vestidas, representando las garantías, derramaban sobre el carro frescas flores. ${ }^{62}$

Seguramente los hijos de Ana e Iturbide; Agustín Gerónimo, Sabina, Juana, Josefa, Ángel, María del Jesús y Salvador, fueron con ella, ataviados como pequeños militares y bellas princesas, que ante la atenta mirada de sus vecinos y amigos celebraban aquel inusitado desfile. La esposa del primer jefe del Ejército Trigarante regresaba a su ciudad y "la artillería hacía subir el estruendo al cielo". 63

En la casa paterna aguardaba el viejo Isidro Huarte, quien deseoso esperó el carro de "doña Ana [que] tardó poco más de una hora en llegar", ${ }^{64}$ y de aquellas puertas fastuosas salieron a recibirla todas las ricas damas de Valladolid, puestas con primor, ${ }^{65}$ con aquel lujo que

${ }^{62}$ Anónimo, Entrada publica en Valladolid de la señora doña Ana Huarte de Iturbide, digna esposa del inmortal héroe mexicano, en Fernández de Córdoba, Joaquín, Verdadero origen de la imprenta en Morelia, pp. 36-37. Nota: Lamina número 7. El folleto dividido en dos partes ensalza la entrada de Ana Huarte a Valladolid, en aras de la capitulación de la Ciudad de México a manos de Agustín de Iturbide.

${ }^{63}$ Anónimo, Entrada publica en Valladolid de la señora doña Ana Huarte de Iturbide, digna esposa del inmortal héroe mexicano.

${ }^{64}$ Anónimo, Entrada publica en Valladolid de la señora doña Ana Huarte de Iturbide, digna esposa del inmortal héroe mexicano.

${ }^{65}$ Navarro Méndez, "Ana María Huarte de Iturbide”, p. 37. 
les era tan propio. El cabildo eclesiástico decidió oficiar una misa a su llegada, ${ }^{66}$ y la invitó a asistir en lo sucesivo a recibir la eucaristía en catedral, ya que gozaba de un espacio especial para ella, frente al árbol evangélico. Concluida la misa, la celebración comenzó de inmediato en la casa paterna;

...al entrar en el salón que estaba preparado rompió una sinfonía ejecutada por hábiles profesores. [Así] comenzaron [a] llegar todas las corporaciones a cumplimentarla: el muy ilustre y venerable cabildo eclesiástico en cuerpo; [...] el muy ilustre Ayuntamiento bajo de meza; los reverendos padres prelados de las sagradas religiones; el Colegio Seminario, etcétera. [Tras esto] se sirvió un espléndido refresco; enseguida se dio un gran concierto en el que el divino [José Mariano] Elízaga tuvo en suspensos y arrebatados los ánimos largo rato; por último, se entonaron canciones patrióticas y otras piezas de mucho gusto. ${ }^{67}$

El derroche que vivió Valladolid en esos momentos se asemeja a los que se vivía ante la jura del rey español, si bien, la folletería afirma que los vallisoletanos nunca habían visto tanto lujo y esplendor. El hecho se puede entender bajo dos aspectos y es que en primera instancia el recibimiento de la esposa de Iturbide - el héroe de Iguala y quien en ese momento abanderaba la Independencia de México- ameritaba un recibimiento de tal magnitud, pues si se quiere observar desde el lado romántico, ella capituló a Valladolid de Michoacán y él a México. Y, en segundo término; la creciente idealización de ver a Iturbide coronado,

66 "Sesión de cabildo eclesiástico, misa a Ana Huarte", 20 de agosto de 1821, ACCM, Actas de Cabildo, libro 47, año 1819-1821, ff. 168 v-175 v.

${ }^{67}$ Anónimo, Entrada publica en Valladolid de la señora doña Ana Huarte de Iturbide, digna esposa del inmortal héroe mexicano. 
idea de la cual se comenzaba a hablar, pues él mismo menciona en sus memorias escritas en el extranjero que la pesadez de la corona ya se cernía en él desde antes de la entrada a la Imperial Ciudad de México. ${ }^{68}$

Si bien, es cierto que el destino político de Iturbide no estaba escrito, el contexto que se construyó a lo largo de 1821 y 1822 proyectó la idea de entronizar a Agustín de Iturbide, concretándose en la arenga pública de mayo de 1822, tras los actos que apasionaron a la sociedad esa noche. Ana Huarte se trasformaría, por la gracia del Congreso Imperial, en emperatriz de Anáhuac.

\section{Conclusiones}

¿Qué no decir de Ana María Huarte que no involucre a Iturbide? francamente casi nada, pero hemos querido mostrar la vida de una mujer a través de los ojos de un historiador y no de un novelista o de un literato. Ana representa el reflejo de la invisibilidad femenina dentro de los anales de la historiografía académica, de ahí el reto que asumimos en este pequeño escrito, reafirmando la necesidad de los estudios históricos sobre la mujer.

Debemos darnos a la tarea de reconstruir la vida de los actores femeninos que estuvieron inmersos en los acontecimientos, con la intención de tener una mayor comprensión de los procesos. Hemos intentado el rescate de uno de tantos personajes olvidados y menospreciados en nuestra historia e historiografía, no solo con la finalidad de reivindicar y ponderar su figura; sino para tratar de comprender

\footnotetext{
${ }^{68}$ Villavicencio, Carrera militar y política de don Agustín de Iturbide, pp. 26-27. Nota: Si bien, el trabajo de Villavicencio recupera algunas ideas sobre lo que Agustín de Iturbide escribió mientras permaneció en el exilio en Liorna, las apreciaciones son casi una calca de la obra que Iturbide dejo como legado. Por otro lado, el trabajo de Villavicencio está sujeto a una crítica que nosotros hemos detectado, pues su obra ha sido mal señalada y puntualizada como si fuese de la autoría del vallisoletano: Spence Robertson cometió el error de señalar que el libro fue redactado por el mismo Iturbide.
} 
y explicar las transformaciones que experimentaron muchas mujeres en aquella sociedad en transición. Si bien no podemos enfatizar de manera certera las particularidades de la vida de Ana María Huarte, podemos reflexionar sobre el papel histórico de una mujer tan singular y excepcional como lo fue ella.

No hay que ver la vida de la mujer del emperador como un remanente de una moraleja histórica - por su marido la familia pagó y murió miserable--. Aunque sea cierto esto último, creemos que ella, bien refleja el prototipo de la mujer novohispana de los siglos XVIIIxix, un personaje desconocido que dio de qué hablar en el Congreso en varias ocasiones. Ana era el preámbulo de la vida y de las decisiones de Agustín de Iturbide, con sus nueve hijos detonó la particularidad de la mujer y madre mexicana, una fémina y una esposa que pese al haber perdido todo, nunca mostró miedo alguno ante el destino que afrontaría años después: la existencia de una viuda, de una desterrada de su patria, y que según la prosa de Iturbide "Ana, santa mujer" desafió a quienes atropellaron su existencia, muriendo sola y en completo olvido para la memoria mexicana.

Aún quedan muchas aristas por resolver sobre la vida de Ana Huarte, los aportes historiográficos e históricos deben ahondar más en la vida de la mujer del emperador, los semblantes de su vida pueden revelar más de la construcción política del México decimonónico en cuanto a la mujer. Ana María Huarte, luego de la muerte de Agustín de Iturbide y de perderlo casi todo, luchó por conseguir sus derechos negados, mostrando su fortaleza e integridad ante los embates políticos que enfrentó. 


\section{Fuentes}

\section{Archivos}

ACCM Archivo Capitular de la Catedral de Morelia

AHMM Archivo Histórico Municipal de Morelia

APSM Archivo de la Notaria Parroquial del Sagrario de Morelia

AHGMo Archivo Histórico Casa de Morelos

APSMM Archivo de la Parroquia del Sagrario Metropolitano de México

APSAQ Archivo de la Notaria Parroquial de la Iglesia de Santa Ana de Santiago Querétaro

APSMAM Archivo Parroquial de San Miguel de Arcángel México

\section{Bibliografía}

Alamán, Lucas, Disertaciones sobre la historia de Méjico, México, Imprenta de Agüeros, 1899.

Archivo General de la Nación, Documentos para la historia de la guerra de Independencia, 1810-1821. Correspondencia y diario militar de Iturbide, 1810-1813, t. I, México, Imprenta Manuel León Sánchez, 1923.

Archivo General de la Nación, Documentos para la historia de la Guerra de Independencia, 1810-1821. Correspondencia y diario militar de Iturbide, t. III, México, Archivo General de la Nación, 1926.

Arenal Fenochio, Jaime del, Un modo de ser libres. Independencia y Constitución en México (1816-1821), México, Instituto Nacional de Estudios Históricos de las Revoluciones de México-El Colegio de Michoacán, 2010 .

Arrom, Silvia, Las mujeres de la Ciudad de México 1790-1857, México, Siglo xxi editores, 1988. 
Ávila, Alfredo, En nombre de la Nación. La formación del Gobierno Representativo en México, México, Centro de Investigaciones y Docencia Económicas-Taurus, 2002.

Beltrán, Rosa, La corte de los ilusos, México, Booket, 2010.

Bustamante Carlos María de, Cuadro histórico de la Revolución mexicana de 1810, México, Imprenta de Mariano Lara, 1843.

Carreño Alvarado, Gloria, El Colegio de Santa Rosa de Valladolid 1743-1819, México, Universidad Michoacana de San Nicolás de Hidalgo (Colección Historia Nuestra), núm. 2, 1979.

Cuevas, Mariano, El libertador: Documentos selectos de Don Agustín de Iturbide, México, Patria, 1947.

E. Anna, Timothy, El Imperio de Iturbide, México, Consejo Nacional para la Cultura y las Artes-Alianza Editorial, 1991.

Fernández Córdoba de, Joaquín, Verdadero origen de la imprenta en Morelia. Reproducciones facsimiles de los primeros impresos vallisoletanos de 1821, México, 1949.

Fernández Lizardi de, José Joaquín, La educación de las mujeres o La quijotita y su prima. Historia muy cierta con apariencias de novela, México, J. Ballescá y Compañía, 1897.

Gonzalbo Aizpuru, Pilar, Historia de la educación en la época colonial. La educación de los criollos y vida urbana, México, El Colegio de MéxicoCentro de Estudios Históricos, 2014.

Gonzalbo Aizpuru, Pilar, "Orden, educación y mala vida en la Nueva España”, en Historia Mexicana, vol. 63, núm. 1 (249), julio-septiembre 2013, pp. 7-50. 
Gutiérrez Casillas, José, Papeles de don Agustín de Iturbide, hallados recientemente, México, Tradición, 1977.

Guzmán Pérez, Moisés y Barbosa Malagón, Paulina Patricia, "Lecturas femeninas en Valladolid de Michoacán (siglo xvini). La 'librería' de Ana Manuela Muñiz Sánchez de Tagle”, en Tzintzun. Revista de Estudios Históricos, núm. 58, julio-diciembre, 2013, pp. 15-70.

Guzmán Pérez, Moisés, "El movimiento Trigarante y el fin de la guerra en la Nueva España", en Anuario Colombiano de Historia Social y de la Cultura, núm. 41. 2, pp. 131-161.

Guzmán Pérez, Moisés, Miguel Hidalgo y el gobierno insurgente en Valladolid, México, Instituto de Investigaciones Históricas-Universidad Michoacana de San Nicolás de Hidalgo (Colección Bicentenario de la Independencia núm. 11), 2011.

, Historia Ilustrada de la Guerra de Independencia de Michoacán, "Las Mujeres michoacanas en la Independencia", núm. 11, México, Instituto de Investigaciones Históricas-Universidad Michoacana de San Nicolás de Hidalgo-Gobierno del Estado de Michoacán de Ocampo-Secretaría de Educación del Estado, 2010.

Juárez Nieto, Carlos, La oligarquía y el poder político en Valladolid de Michoacán, 1785-1810, México, Instituto Nacional de Antropología e Historia-Instituto Michoacano de la Cultura-Congresos del Estado de Michoacán, 1994.

Malo, José, Apuntes sobre el destierro, vuelta al territorio mexicano y muerte del libertador don Agustín de Iturbide, México, Imprenta de la Revista Universal, 1869.

Navarro Méndez, José María, "Ana María Huarte de Iturbide y su entrada a Valladolid, 1821", en Rosa de los Vientos, Vida Cotidiana en el Centro Histórico de Morelia, núm. 7, 2016, pp. 31-40. 
, "La mujer del emperador. Ana María Huarte de Iturbide

(1786-1861). Una biografía histórica", tesis de licenciatura, Morelia, Universidad Michoacana de San Nicolás de Hidalgo-Facultad de Historia, 2015.

Núñez y Domínguez, José de Jesús, La virreina mexicana, México, Universidad Nacional Autónoma de México, 1950.

Perrot, Michelle, Mi historia de las mujeres, México, Fondo de Cultura Económica, 2009.

Rocafuerte, Vicente, Bosquejo ligerísimo de la Revolución de Mégico, desde el grito de Iguala hasta la proclamación de Iturbide, Estados Unidos de América, 1822.

Rodríguez, Martha Eugenia, "Costumbres y tradiciones en torno al embarazo y al parto en el México virreinal", en Anuario de Estudios Americanos, núm. 2, vol. 57, España, Escuela de Estudios Hispano-Americanos-Consejo Superior para la Investigación Científica, 2000.

Spence Robertson, William, Iturbide de México, México Fondo de Cultura Económica, 2002.

Vega, Juanino Josefa, Agustín de Iturbide, España, Historia 16: Quórum, 1987.

Villavicencio, Carrera militar y politica de don Agustín de Iturbide, México, Imprenta de la Ex Inquisición a cargo de Manuel Ximeno, 1827. 